\title{
The Effectiveness of China's Plug-In Electric Vehicle Subsidy
}

\section{Tamara Sheldon and Rubal Dua}




\section{About KAPSARC}

The King Abdullah Petroleum Studies and Research Center (KAPSARC) is a non-profit global institution dedicated to independent research into energy economics, policy, technology and the environment across all types of energy. KAPSARC's mandate is to advance the understanding of energy challenges and opportunities facing the world today and tomorrow, through unbiased, independent, and high-caliber research for the benefit of society. KAPSARC is located in Riyadh, Saudi Arabia.

This publication is also available in Arabic.

\section{Legal Notice}

(C) Copyright 2019 King Abdullah Petroleum Studies and Research Center ("KAPSARC"). This Document (and any information, data or materials contained therein) (the "Document") shall not be used without the proper attribution to KAPSARC. The Document shall not be reproduced, in whole or in part, without the written permission of KAPSARC. KAPSARC makes no warranty, representation or undertaking whether expressed or implied, nor does it assume any legal liability, whether direct or indirect, or responsibility for the accuracy, completeness, or usefulness of any information that is contained in the Document. Nothing in the Document constitutes or shall be implied to constitute advice, recommendation or option. The views and opinions expressed in this publication are those of the authors and do not necessarily reflect the official views or position of KAPSARC. 


\section{Key Points}

ubsidies for promoting plug-in electric vehicle (PEV) adoption are a key component of China's overall plan for reducing local air pollution and greenhouse gas (GHG) emissions from its light-duty vehicle sector. This paper explores the impact and cost-effectiveness of the Chinese PEV subsidy program. A vehicle choice model is estimated using a large random sample of individual-level data for new vehicle purchases in China for model year 2017. The vehicle choice model is then used to predict the PEV market share under alternative policies. Simulation results suggest that:

PEVs have improved China's new vehicle fleet fuel economy by roughly $2 \%$, reducing total gasoline consumption by some 6.66 billion liters, assuming a vehicle life of 14.5 years.

The current PEV subsidy in China is expensive, costing US\$1.90 per additional liter of gasoline saved. This is due to a large number of non-additional PEV buyers, particularly high income consumers, who would have purchased the PEV regardless of the subsidy. Similar findings have been observed for the federal PEV subsidy in the United States (U.S.).

A targeted subsidy design, similar to California's PEV subsidy, involving eliminating subsidies for high income consumers and a higher subsidy for low income consumers could result in a lower cost per additional PEV (US\$13,758 versus US\$ 24,506). This would allow for slightly greater PEV adoption ( $3.11 \%$ versus the current $2.47 \%$ market share) for the same budget.

Figure 1. The impact and cost-effectiveness of China's PEV subsidy.

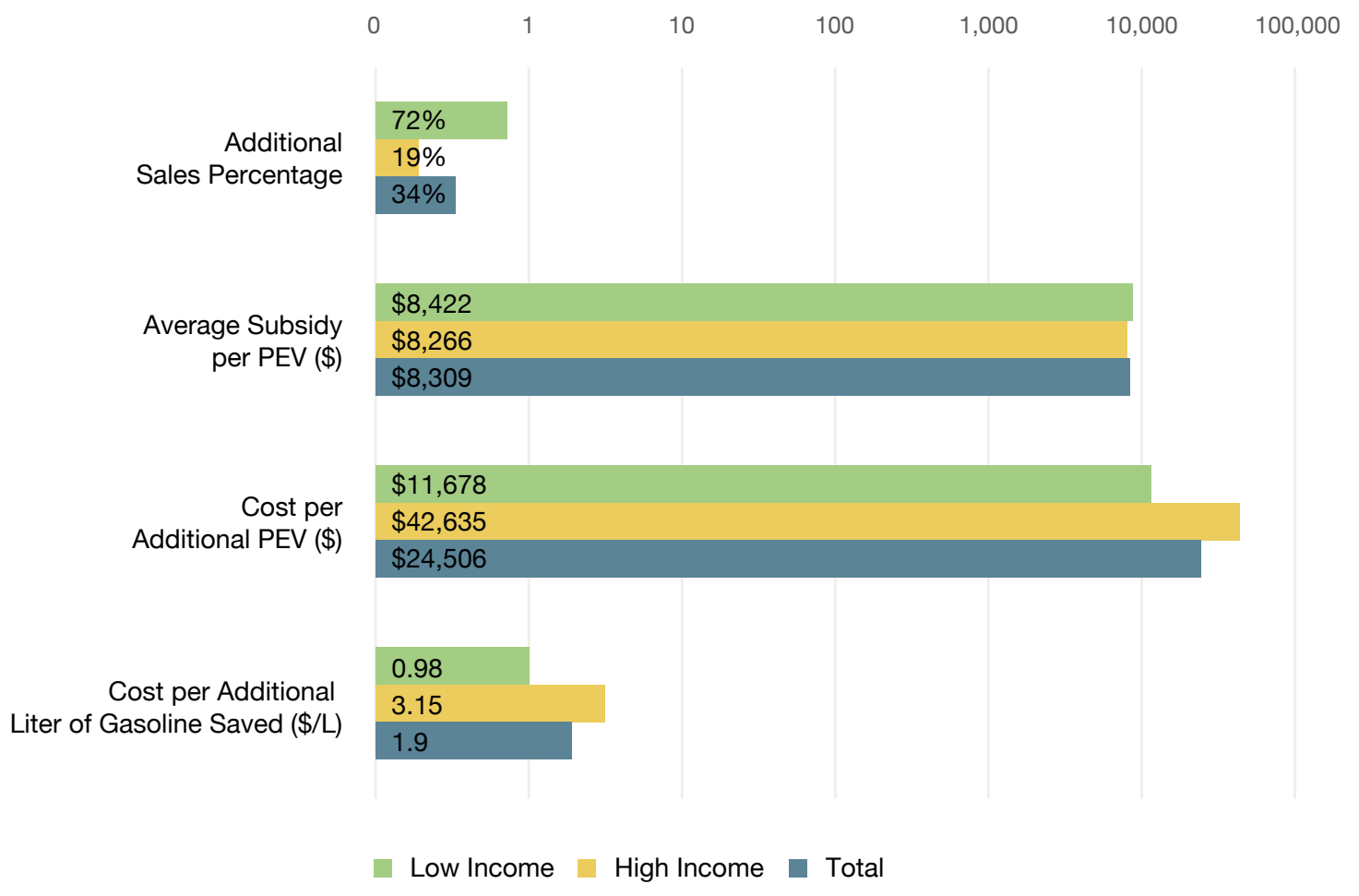

Source: KAPSARC analysis. 


\section{Summary}

C hina, the world's largest emitter of carbon dioxide, has announced ambitious climate goals in recent years. These include reducing the carbon intensity of its gross domestic product (GDP) by $40 \%-45 \%$ of 2005 levels by 2020 and by $60 \%-65 \%$ of 2005 levels by 2030 (Xu, Chen, and Chen 2017). One component of China's overall plan to reduce carbon emissions is its "New Energy Vehicle Policy," a multi-pronged policy to increase the share of battery electric vehicles (BEVs), plug-in hybrid electric vehicles (PHEVs), and fuel cell vehicles. Since 2009, plug-in electric vehicles (PEVs, which include BEVs and PHEVs) qualify for substantial rebates (up to US\$9,000) from both the central and local governments (ICCT 2017a). Furthermore, in several big cities such as Shanghai and Shenzhen, PEVs are exempt from new vehicle registration lotteries and fees (ICCT 2017b). These policies have led to significant PEV market share growth in recent years, with PEVs accounting for $\sim 2.5 \%$ of new vehicle sales in 2017 .

Despite China's ambitious goal to have five million new energy vehicles (NEVs) on the road by 2020 , there is some uncertainty over the future of its electric vehicle subsidy program. This paper explores the impact of these subsidies to assist the policy discussion, especially given the uncertainty surrounding the future of China's electric vehicle subsidy program. A vehicle choice model is estimated using a large, random survey sample of new vehicle purchases in China. The estimation results are used to predict PEV sales if subsidies were eliminated and if subsidies were targeted towards low income consumers. The findings suggest that PEVs have improved China's new vehicle fleet fuel economy by roughly $2 \%$, reducing total gasoline consumption by roughly 6.66 billion liters. However, the current PEV subsidy is expensive, costing US\$1.90 per liter of gasoline reduction. This is due to a large number of nonadditional PEV buyers, particularly high income consumers, who would have purchased the PEV regardless of the subsidy. Similar findings have been observed for the federal PEV subsidy in the United States. Eliminating the subsidy for high income consumers, similar to the targeted subsidy designs adopted by the state of California, and increasing it for low income consumers could result in a lower cost per additional PEV (US\$13,758 versus the current US\$24,506). This would allow for slightly greater PEV adoption (3.11\% versus the current $2.47 \%$ market share) for the same budget. 


\section{Introduction}

here have been several recent updates to China's plug-in electric vehicles (PEV) policy. PEV rebates fell by $20 \%$ per year from 2017 to 2020, and the technological requirements of PEVs became more stringent. Second, anti-fraud and enforcement measures were implemented to address concerns about subsidy fraud (ICCT 2017a). Third, in September 2017, China finalized a new energy vehicle (NEV) mandate policy targeting vehicle manufacturers. Under the mandate, effective from 2019, all large manufacturers (producing or importing at least 30,000 passenger cars annually) must achieve NEV targets of 10\% in 2019 and $12 \%$ in 2020 . These targets are not for NEV production but for NEV credits, where each NEV produced qualifies for up to six credits based on characteristics such as range and energy efficiency. The resulting NEV market share would likely be lower than the target percentage (e.g., a 4\% market share could achieve the $12 \% 2020$ target based on NEV credits) (ICCT 2018).
Studies have shown that various government policies, including subsidies, preferential taxes, parking and driving perks, have positively impacted NEV adoption in China (Zhang et al. 2011; Helveston et al. 2015; Sang and Bekhet 2015; Li, Long and Chen 2016; Wang, Pan and Zheng 2017). However, little is known about the impact and the costeffectiveness of these policies. In spite of China's ambitious goal to have five million NEVs on the road by 2020 , there is some uncertainty over the future of its electric vehicle subsidy program, with some reports suggesting that it will be terminated in the near future (Fusheng 2019; Malone 2018). This paper seeks to shed light on the effectiveness of these subsidies and help inform policy makers, in the face of an uncertain future for China's electric vehicle subsidy program. 


\section{Data}

$\mathrm{T}$ he primary data set, purchased from J.D. Power and Associates, is a survey of Chinese consumers who purchased a new vehicle in model year 2017 (between October 2016 and June 2017). The data includes 65,592 individuals in China who were randomly selected to participate in the survey. Vehicle-specific variables include the make, model, price, fuel consumption, transmission type, engine size, drive system, and the segment of the new vehicle. Three additional vehicle characteristics, curb weight, fuel tank capacity and electric range, were taken from the websites Chinaautoweb, Chinamobil, BitAuto and wattev2buy.com. For plug-in hybrid electric vehicles (PHEVs), a utility factor of 0.5 was assumed for calculating the combined fuel economy (harmonic mean of fuel economy in electric and gasoline modes). For pure battery electric vehicles (BEVs), the fuel (electricity) consumption was based on the BEVs' energy efficiency reported in kilowatts per 100 kilometers $(\mathrm{kWh} / 100 \mathrm{~km})$. A gasoline price of US\$ 0.96 per liter and an electricity price of US\$ 0.09 per kWh are assumed (The World Bank 2016; Statista 2018). Consumer characteristics include gender, age, income range, area (north, south, east, or west), city of residence, the number of cars in the consumer's household, and the number of people in the consumer's household. Months of ownership and the odometer reading at the time of the survey were also collected, from which annual vehicle kilometers traveled (VKT) are calculated. Survey weights make the sample representative of the national new vehicle market. The aggregate new vehicle market shares by model are obtained from bestsellingcarsblog.com.

Table 1 shows the summary statistics of the vehicles in the sample. The average new vehicle price in the sample is 173,238 renminbi (RMB) (approximately

Table 1. Vehicle characteristics.

\begin{tabular}{l|c|c|c|c|c} 
& Obs & Mean & Std. Dev. & Min & Max \\
\hline Price (RMB) (US\$) & 23,680 & $173,238(25,641)$ & $144,720(21,420)$ & $20,000(2,960)$ & $2,350,000(347,828)$ \\
\hline Fuel Consumption (liters/100k) & 23,416 & 8.4 & 1.9 & 3 & 25 \\
\hline Engine Size (liters) & 23,991 & 1.7 & 0.9 & 4 \\
\hline Manual & 23,993 & $32 \%$ & & \\
\hline 4WD & 23,993 & $8 \%$ & & \\
\hline Luxury & 23,993 & $13 \%$ & & \\
\hline Compact-Small Car & 23,993 & $13 \%$ & & \\
\hline Mid-Large Car & 23,993 & $51 \%$ & & & \\
\hline Compact-Small SUV & 23,993 & $23 \%$ & & & \\
\hline Mid-Large SUV & 23,993 & $2 \%$ & & &
\end{tabular}

Note: Obs=observations; Std. Dev=standard deviation; 4WD=four wheel drive; SUV=sports utility vehicle.

Source: KAPSARC analysis. 
25,641 2017 US\$) with a large standard deviation.

The most popular body type is a midsize to large car.

Table 2 shows the summary statistics of the consumers in the sample. These are broken down by income and region. Low and high income correspond to monthly income under and over RMB 16,000 (US\$ $2,368)$, respectively. Note that the majority of new car buyers tend to have substantially higher incomes than the general population (the median monthly income in China is well below RMB 16,000 [US\$2,368] [Wen 2018]), so these relative income categories are with respect to the new car buying population. The highest share of young car buyers is in the east, the highest share of middle-aged car buyers is in the south, and the highest share of older car buyers is in the north. The average household size is largest in the south, and the average VKT is highest in the west. On average, high income consumers have larger households and VKTs. The vast majority of new car buyers in China are part of single car households.

Only about $7 \%$ of the low income new car buyers have more than one car in their household, compared to $13 \%$ for high income households.

PEVs qualify for significant subsidies in the form of rebates from the national and local governments. Before 2016, national subsidies were up to RMB 55,000 (US\$ 8,140) for BEVs and RMB 30,000 (US\$ 4,440) for PHEVs. Local governments could match the national subsidies, effectively doubling them. In 2017, the national subsidy was reduced to a maximum of RMB 48,000 (US\$7,105) for BEVs and RMB 24,000 (US\$ 3,552) for PHEVs, of which local

Table 2. Consumer characteristics.

\begin{tabular}{|c|c|c|c|c|c|c|c|c|}
\hline Low income & Obs & Female & Age 18-28 & Age 29-38 & Age 39+ & $\begin{array}{c}\text { Multi car } \\
\text { HH }\end{array}$ & $\begin{array}{l}\text { Household } \\
\text { size (mean) }\end{array}$ & $\begin{array}{c}\text { Annual VKT } \\
\text { (mean) }\end{array}$ \\
\hline North & 3,010 & $45 \%$ & $27 \%$ & $50 \%$ & $24 \%$ & $7 \%$ & 3.0 & 12,706 \\
\hline South & 998 & $45 \%$ & $37 \%$ & $51 \%$ & $12 \%$ & $7 \%$ & 3.4 & 13,014 \\
\hline East & 3,592 & $37 \%$ & $42 \%$ & $43 \%$ & $14 \%$ & $10 \%$ & 3.1 & 13,324 \\
\hline West & 2,478 & $37 \%$ & $28 \%$ & $54 \%$ & $18 \%$ & $5 \%$ & 3.2 & 15,024 \\
\hline Total & 10,078 & $40 \%$ & $34 \%$ & $48 \%$ & $18 \%$ & $7 \%$ & 3.1 & 13,527 \\
\hline High income & Obs & Female & Age 18-28 & Age 29-38 & Age 39+ & $\begin{array}{c}\text { Multi car } \\
\text { HH }\end{array}$ & $\begin{array}{l}\text { Household } \\
\text { size (mean) }\end{array}$ & $\begin{array}{c}\text { Annual VKT } \\
\text { (mean) }\end{array}$ \\
\hline North & 2,014 & $46 \%$ & $22 \%$ & $53 \%$ & $26 \%$ & $15 \%$ & 3.1 & 15,040 \\
\hline South & 2,763 & $42 \%$ & $20 \%$ & $66 \%$ & $13 \%$ & $14 \%$ & 3.6 & 14,657 \\
\hline East & 5,486 & $43 \%$ & $25 \%$ & $56 \%$ & $18 \%$ & $14 \%$ & 3.2 & 13,144 \\
\hline West & 3,652 & $39 \%$ & $23 \%$ & $56 \%$ & $21 \%$ & $10 \%$ & 3.3 & 15,478 \\
\hline Total & 13,915 & $42 \%$ & $23 \%$ & $58 \%$ & $19 \%$ & $13 \%$ & 3.3 & 14,331 \\
\hline
\end{tabular}

Note: Obs=observations; $\mathrm{HH}=$ household; VKT=vehicle kilometers traveled.

Source: KAPSARC analysis. 
governments can only match 50\% (ICCT 2017a). For BEVs with a battery density under 120 watt hours per kilogram $(\mathrm{Wh} / \mathrm{kg})$, the national subsidy is RMB 20,000 (US\$2,960) for BEVs with an electric range between $100 \mathrm{~km}$ and $150 \mathrm{~km}$, RMB 36,000 (US\$ 5,328) for BEVs with an electric range between $150 \mathrm{~km}$ and $250 \mathrm{~km}$, and RMB 44,000 (US\$ 6,513) for $\mathrm{BEVs}$ with an electric range exceeding $250 \mathrm{~km}$. For BEVs with battery densities greater than $120 \mathrm{Wh} / \mathrm{kg}$, the corresponding subsidies are RMB 22,000 (US\$
3,256), RMB 40,000 (US\$ 5,920), and RMB 48,000 (US\$ 7,105). There was no information on battery density of the PEV sample, so current national incentives are assumed to be the average values of the two battery density categories: RMB 21,000 (US\$ 3,108), RMB 38,000 (US\$ 5,625), and RMB 46,000 (US\$ 6,809) for the low, medium, and high range $\mathrm{BEV}$, respectively. PHEVs with an electric range greater than $50 \mathrm{~km}$ qualify for a subsidy of $\mathrm{RMB}$ 24,000 (US\$ 3,552). 


\section{Methodology}

n exploratory analysis revealed that out of the observable demographic variables, preferences vary mostly by income. This is consistent with similar studies on new vehicle consumers in other countries such as the U.S. (e.g., Sheldon and Dua 2018a, 2018b; DeShazo, Sheldon, and Carson 2017). The sample is therefore divided up into two subsamples - low and high income (below and above RMB 16,000 [US\$2,368]). Vehicle choice models and market share predictions are estimated separately for each subsample. Despite the random sampling in the survey, it had only five PEV respondents. Thus, we based PEV sales on a survey of PEV buyers in China from Xing et al. (2016). Based on this survey's reported results, a 40-60 split between low and high income consumers was used for lower-end PEVs with a manufacturer's suggested retail price (MSRP) of less than RMB 154,900 (US\$ 22,927), and a 15-85 split was used for the rest of the PEVs. For example, assume there are 100 survey respondents in Xing et al. (2016) for each PEV model. For each PEV model with an MSRP less than RMB 154,900 (US\$22,927), 40 respondents were assigned to the low income group and 60 to the high income group. For each PEV model with an MSRP greater than RMB 154,900 (US\$ 22,927), 15 respondents were assigned to the low income group and 85 to the high income group. The sales weight for each PEV model was the total sales for that PEV model divided by 100 .

Choice sets are constructed at the make and model level. For each model, price and vehicle attributes are the sales weighted average of all model observations. For each subsample, following Sheldon and Dua (2018b), a conditional logit model is estimated using the following utility function for vehicle $i$, with observations weighted by survey weights:

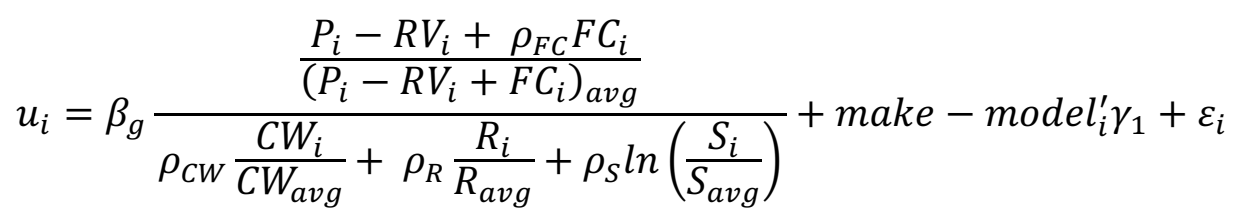

where

$P_{i}:$ Price

$R V_{i}:$ Net present value of resale price

$F C_{i}:$ Net present value of fuel costs

$C W_{i}:$ Curb weight

$R_{i}$ : Range

$S_{i}$ : Previous year sales

$\rho_{x}$ : Weights for respective vehicle characteristics

make-model $_{i}$ : Vector of make-model indicators 
The top numerator, price minus resale value plus refueling costs, represents the total cost of ownership. The 'popularity' term Si accounts for spillover effects (Tucker and Zhang 2011). Refueling costs are calculated using the vehicle's fuel consumption rate and consumer VKT, assuming a fuel cost of US\$ 0.96 per liter and a vehicle holding period of 7.5 years. The vehicle holding period assumption is based on the average new vehicle holding period calculated using new vehicle experience study data for the U.S. market. Given the lack of such data for the Chinese market, the U.S. data assumption was applied to Chinese consumers. However, given their relatively lower purchasing power, Chinese consumers might choose to hold on to their vehicle longer than American consumers. Following Leard et al. (2017), a real market interest rate of $1 \%$ is assumed in the calculations of resale value and the net present value of fuel costs. Attributes are normalized by dividing by average values to avoid issues of scale. $\varepsilon_{j}$ is assumed to be an independently distributed Type-I extreme value error. As discussed in detail in Sheldon and Dua (2018a, 2018b), a combined attribute variable as shown in Equation 1 avoids attribute multi-collinearity issues associated with a linear utility function separable in attributes. $\beta_{g}$ has a negative expected sign as the numerator (price and fuel costs) has a negative expected sign, and the denominator (performance characteristics) has a positive expected sign.

The choice model is estimated as follows. First, a conditional logit model is estimated assuming the initial values of $\rho>0$ and excluding make-model indicators. One $\rho$ is changed by a small delta and the conditional logit re-estimated. If the change improves the Akaike and Bayesian information criteria (AIC and BIC), the parameter is updated. In an iterative process, the set of $\rho$ values is updated until no significant change in $\mathrm{AIC}$ and $\mathrm{BIC}$ is observed. Second, the $\rho$ values are constrained to their AIC/BIC optimized values, and a conditional logit is estimated for the full utility function shown in Equation 1.

Finally, two counterfactual simulations are performed with the baseline estimates. First, subsidies are removed from the PEV prices to predict hypothetical PEV sales if subsidies were eliminated. Second, an alternative subsidy schedule is simulated wherein the total policy budget remains the same (US $\$ 4.28$ billion), but all subsidies are allocated to the low income group of consumers and are higher than existing subsidies. 


\section{Results}

able 3 displays the coefficient estimates used to carry out the counterfactual policy simulations. Table 4 compares the predicted counterfactual fleet if PEVs were unavailable for purchase in China to the current fleet with existing subsidies in China. Without PEVs, fleet fuel economy would be 12.38 kilometers per liter $(\mathrm{km} / \mathrm{l})$, roughly $2 \%$ lower than the current $12.62 \mathrm{~km} / \mathrm{l}$, with most of the improvement coming from high income consumers who are more likely to purchase PEVs. Assuming a vehicle lifetime of 14.5 years (Hao et al. 2011), the PEV subsidies are estimated to reduce gasoline consumption by 6.66 billion liters (based on reported consumer VKT). The total cost of the PEV subsidy is US\$ 4.29 billion, assuming each consumer who purchases a PEV applies for and receives the subsidy. High income consumers receive more than two thirds of the subsidy dollars. The implied cost per liter of gasoline saved is US\$ 0.64 (US\$ 4.29 billion/6.66 billion liters). However, many PEV buyers are 'non-additional' as they would have purchased the PEV even without the subsidy. Estimates suggest that, all else being equal, 34\% of existing PEV buyers are additional, or were induced by the subsidy to purchase the PEV. This equates to a cost per additional liter of gasoline saved of US\$ 1.90 (US\$ 4.29 billion/[0.34*6.66 billion liters]). Note that, when not accounting for additionality, the cost per liter of gasoline saved is similar across income groups: US\$ 0.71 and US\$ 0.61 for low and high income consumers, respectively. However, since high income consumers are more likely to purchase a PEV in the absence of a subsidy more subsidy dollars are spent on non-additional high income consumers. As such, the cost per additional liter of gasoline saved as a result of the subsidy is US\$ 0.98 for low income consumers, less than a third of the US\$ 3.15 for high income consumers.

Table 5 shows the PEV market share with the current subsidy schedule and compares it to two alternative policies: eliminating subsidies and

Table 3. Conditional logit estimation results.

\begin{tabular}{c|c|c} 
& Low income & High income \\
\hline$\beta_{g}$ & $-2.304^{* * *}(.0013)$ & $-0.874^{* * *}(.0014)$ \\
\hline$\rho_{F C}$ & 1.145 & 3.660 \\
\hline$\rho_{C W}$ & 1 & 1 \\
\hline$\rho_{R}$ & 0.194 & 1.5 \\
\hline$\rho_{S}$ & 0.101 & 0.165 \\
\hline Make-model indicators & $Y$ & $Y$ \\
\hline Observations & $2,399,129,432$ & $3,036,123,480$
\end{tabular}

Standard errors in parentheses ${ }^{* \star *} p<0.01$

Source: KAPSARC analysis. 
Table 4. Gasoline savings from PEV adoption.

\begin{tabular}{|c|c|c|c|}
\hline & Low income & High income & Total \\
\hline Fleet fuel economy with PEVs $(\mathrm{km} / \mathrm{l})$ & 13.06 & 12.28 & 12.62 \\
\hline Fleet fuel economy without PEVs (km/l) & 12.90 & 11.99 & 12.38 \\
\hline$\%$ change in fleet fuel economy & 1.22 & 2.47 & 1.94 \\
\hline $\begin{array}{l}\text { Liters of gasoline saved (billion liters) (assuming vehicle life } \\
\text { of } 14.5 \text { years) }\end{array}$ & 1.69 & 5.07 & 6.66 \\
\hline Subsidy cost (US\$ billions) & 1.20 & 3.09 & 4.29 \\
\hline Cost per liter of gasoline saved (US\$/I) & 0.71 & 0.61 & 0.64 \\
\hline Cost per additional liter of gasoline saved (US\$/I) & 0.98 & 3.15 & 1.90 \\
\hline
\end{tabular}

Source: KAPSARC analysis.

reassigning all subsidy dollars to the low income group (a 'targeted' subsidy). The rationale behind the second scenario is that, as shown in Table 4, the cost per additional liter of gasoline savings is much lower for low income consumers who receive subsidies. Targeting these more price elastic consumers, who also have a lower probability of buying a PEV with a higher per PEV subsidy, could produce greater gasoline savings at a lower cost.

The first row of Table 5 shows that without subsidies, the total PEV market share in China would be $1.63 \%$. The PEV market share for high income consumers, however, would be much larger than that for low income consumers, at $2.58 \%$ against $0.43 \%$, respectively. The current subsidies increase the total PEV market share to $2.47 \%$, with a larger increase in the market share for low income consumers. This is because low income consumers have a higher price elasticity of demand and are more responsive to an effective reduction in PEV prices. Implementation of the subsidies increases the low income PEV market share from $0.43 \%$ to $1.53 \%$. This means that $72 \%$ of PEV purchases ([1.53\%-0.43\%]/1.53\%) by low income consumers under the current subsidy are additional, i.e., caused by the subsidy, and $28 \%$ of low income PEV buyers would have purchased the PEV regardless, yet still receive the subsidy. Since the 'no subsidy' PEV market share is larger for high income consumers (2.58\%) and increases less with the subsidy (to $3.21 \%$ ), only $19 \%$ of high income PEV buyers are additional under the current subsidy because high income consumers are less price responsive.

All PEV buyers, both additional and non-additional, receive the subsidy because it is impossible for the government to determine who is additional. The total subsidy cost under the current policy is US\$ 4.29 billion. Dividing the total subsidy cost by the number of additional sales resulting from the policy yields the cost per additional PEV of US\$24,506. 
Table 5. Improving the impact and cost-effectiveness through targeted subsidy design.

\begin{tabular}{|c|c|c|c|c|}
\hline & & Low income & High income & Total \\
\hline No subsidy & PEV market share (\%) & 0.43 & 2.58 & 1.63 \\
\hline \multirow{4}{*}{ Current subsidy } & PEV market share (\%) & 1.53 & 3.21 & 2.47 \\
\hline & Additional sales percentage & 72 & 19 & 34 \\
\hline & Subsidy cost (billion US\$) & 1.20 & 3.09 & 4.29 \\
\hline & Cost per additional PEV (US\$) & 11,678 & 42,635 & 24,506 \\
\hline \multirow{4}{*}{ Targeted subsidy } & PEV market share (\%) & 3.78 & 2.58 & 3.11 \\
\hline & Additional sales percentage & 89 & 0 & 48 \\
\hline & Subsidy cost (billion US\$) & 4.28 & 0 & 4.28 \\
\hline & Cost per additional PEV (US\$) & 13,758 & 0 & 13,758 \\
\hline
\end{tabular}

Source: KAPSARC analysis.

This is in line with the cost per additional PEV in California of roughly US $\$ 30,000$, as estimated by Deshazo, Sheldon, and Carson (2017). However, due to the large share of high income non-additional consumers, the cost per additional PEV purchase by high income consumers is US\$ 42,335. In contrast, the high percentage of additional sales by low income consumers yields a much lower cost per additional PEV of US\$11,678.

Since lower income consumers account for more PEV adoptions resulting from subsidies, the last simulated policy offers a targeted subsidy $43.5 \%$ higher than the current subsidy to low income consumers and eliminates subsidies for high income consumers. The budget for this policy is approximately equivalent to the total cost of the current subsidy. Under the targeted subsidy, the PEV market share increases to $3.78 \%$ for low income consumers, $89 \%$ of whom are additional. This in turn yields a cost per additional PEV of US\$ 13,758 . Note that this is higher than the US $\$ 11,678$ for low income consumers under the current subsidy because the individual subsidies are greater. However, this amount is just over half the US\$ 24,506 total cost per additional PEV of the current subsidy. Therefore, this targeted subsidy leads to greater PEV adoption than the current subsidy, giving a total PEV market share of $3.11 \%$, against $2.47 \%$ for the current subsidy at the same total policy cost. 


\section{Conclusion}

D espite China's ambitious goal to have five million NEVs on the road by 2020 , there is uncertainty surrounding the future of its subsidy program. This paper seeks to shed light on the effectiveness of these subsidies to assist policy makers in navigating this uncertainty. The paper uses a large random sample of individuallevel, Chinese new vehicle purchases in model year 2017 to estimate a vehicle choice model. To capture consumer heterogeneity, the choice model is estimated separately for low and high income consumers. The choice model is then used to predict the PEV market share in China under various subsidy scenarios.
The findings of this paper suggest that PEVs have improved China's new vehicle fleet fuel economy by roughly $2 \%$, reducing total gasoline consumption by roughly 6.66 billion liters. However, the current PEV subsidy is expensive, costing US $\$ 1.90$ per liter of gasoline reduction. This is due to a large number of non-additional PEV buyers, particularly high income consumers, who would have purchased the PEV regardless of the subsidy. Eliminating the subsidy for high income consumers and increasing it for low income consumers could result in a substantially lower cost per additional PEV (US\$13,758 versus the current US\$24,506). This would allow for greater PEV adoption (3.11\% versus the current $2.47 \%$ market share) for the same budget. 


\section{References}

DeShazo, J.R., Tamara L. Sheldon, and Richard T. Carson. 2017. "Designing Policy Incentives for Cleaner Technologies: Lessons from California's Plug-in Electric Vehicle Rebate Program." Journal of Environmental Economics and Management 84:18-43. https://doi. org/10.1016/j.jeem.2017.01.002

Fusheng, Li. 2019. "Government to ensure new energy car growth in post-subsidy era." http://www.chinadaily. com.cn/a/201901/14/WS5c3bfc30a3106c65c34e4428. html.

Hao, Han, HeWu Wang, MingGao Ouyang, and Fei Cheng. 2011. "Vehicle survival patterns in China." Science China Technological Sciences 54 (3):625-629. doi: 10.1007/s11431-010-4256-1. https://doi.org/10.1007/ s11431-010-4256-1

Helveston, John Paul, Yimin Liu, Elea McDonnell Feit, Erica Fuchs, Erica Klampfl, and Jeremy J. Michalek. 2015. "Will subsidies drive electric vehicle adoption? Measuring consumer preferences in the U.S. and China." Transportation Research Part A: Policy and Practice 73:96-112. https://doi.org/10.1016/j.tra.2015.01.002

International Council on Clean Transportation (ICCT). 2017a. "Adjustment to Subsidies for New Energy Vehicles in China," Policy Update, May. https:// www.theicct.org/sites/default/files/publications/ China-NEV_ICCT_policy-update_17052017_vF.pdf

- - - 2017b. "Electric vehicle capitals of the world: What markets are leading the transition to electric?" Briefing, November. https://www. theicct.org/sites/default/files/publications/ World-EV-capitals_ICCT-Briefing_08112017_vF.pdf

- - - 2018. "China's New Energy Vehicle Mandate Policy (Final Rule)." Policy Update, January. https://www. theicct.org/sites/default/files/publications/ICCT_ChinaNEV-mandate_policy-update_20180111.pdf

Leard, Benjamin, Joshua Linn, and Yichen Christy Zhou. 2017. "How Much Do Consumers Value Fuel Economy and Performance? Evidence from Technology Adoption" Resources for the Future.https://media.rff.org/documents/ RFF-Rpt-WTP_FuelEconomy26Performance.pdf
Li, Wenbo, Ruyin Long, and Hong Chen. 2016.

'Consumers' evaluation of national new energy vehicle policy in China: An analysis based on a four paradigm model." Energy Policy 99:33-41.

Malone, Wade. 2018. "China Expected To Slash EV Subsidies By $30 \%$ Next Year." Inside EVs. https:// insideevs.com/china-will-slash-ev-subsidies-2019/

Sang, Yew-Ngin, and Hussain Ali Bekhet. 2015. "Modelling electric vehicle usage intentions: an empirical study in Malaysia." Journal of Cleaner Production 92:7583. https://doi.org/10.1016/j.jclepro.2014.12.045

Sheldon, Tamara L., and Rubal Dua. 2018.a "Gasoline savings from clean vehicle adoption." Energy Policy 120: 418-424. https://doi.org/10.1016/j.enpol.2018.05.057

---. 2018b. "Drivers of New Light-Duty Vehicle Fleet Fuel Economy in Saudi Arabia." KAPSARC discussion paper, Riyadh, Saudi Arabia. https://doi.org/10.30573/ ks--2019-dp55

Statista. 2018. "Global electricity prices in 2017, by select country (in U.S. dollars per kilowatt hour)." https://www.statista.com/statistics/263492/ electricity-prices-in-selected-countries/

The World Bank. 2016. "Pump price for gasoline (US\$ per liter). https://data.worldbank.org/indicator/EP.PMP. SGAS.CD

Tucker, Catherine, Zhang, Juanjuan. 2011. "How Does Popularity Information Affect Choices? A Field Experiment." Management Science 57:828-842. https:// doi.org/10.1287/mnsc.1110.1312

Wang, Ning, Huizhong Pan, and Wenhui Zheng. 2017. "Assessment of the incentives on electric vehicle promotion in China." Transportation Research Part A: Policy and Practice 101:177-189. https://doi.org/10.1016/j. tra.2017.04.037 
Wen, Yi. 2018. "Income and Living Standards across China." Federal Reserve Bank of St. Louis. https:// www.stlouisfed.org/on-the-economy/2018/january/ income-living-standards-china

Xing, Yan, Gil Tal, Yunshi Wang, Ying Liu, Xiaohua Ding, Pinxi Wang, and Wenjie Wang. 2016. "A Comparison of Plug-in Electric Vehicle Markets Between China and the U.S. Based on Surveys" in Blue Book of New Energy Vehicles 2016, Social Sciences Academic Press (in press).
Xu, Lei, Nengcheng Chen, and Zeqiang Chen. 2017. "Will China make a difference in its carbon intensity reduction targets by 2020 and 2030?" Applied Energy 203:874-882. https://doi.org/10.1016/j.apenergy.2017.06.087

Zhang, Yong, Yifeng Yu, and Bai Zou. 2011. "Analyzing public awareness and acceptance of alternative fuel vehicles in China: The case of EV." Energy Policy 39(11):7015-7024. https://doi.org/10.1016/j. enpol.2011.07.055 
Notes

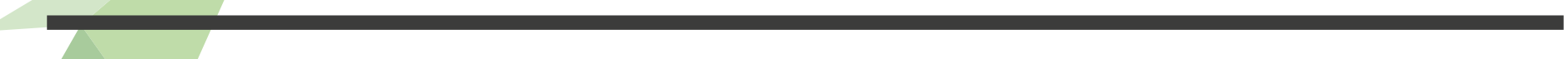




\section{Notes}

(1) 


\section{About the Authors}

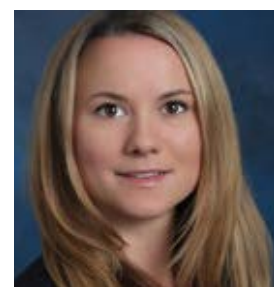

\section{Tamara Sheldon}

Tamara is a visiting researcher at KAPSARC and an assistant professor of economics at the Darla Moore School of Business, University of South Carolina. Her research interests include environmental and energy economics and how these fields interact with public policy. She holds a Ph.D. in Economics from the University of California, San Diego.

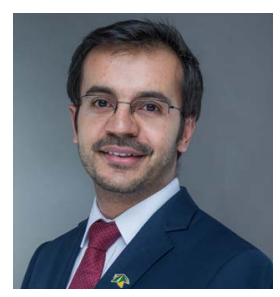

\section{Rubal Dua}

Rubal is a research fellow at KAPSARC working on vehicle regulatory policy and shared mobility research from the consumer perspective. He holds a Ph.D. from KAUST, Saudi Arabia, an M.Sc. from the University of Pennsylvania, and a B.Tech. from the Indian Institute of Technology, Roorkee.

\section{About the Project}

Promoting the adoption of energy-efficient vehicles has become a key policy imperative in both developed and developing countries. Understanding the impact of various factors on adoption rates forms the backbone of KAPSARC's efforts in the light-duty vehicle demand field. These factors include (i) consumer-related factors - demographics, behavioral, and psychographics; (ii) regulatory factors - policies, incentives, rebates, and perks; and (iii) geo-temporal factors - weather, infrastructure, and network effects. Our team is currently developing models at different levels: micro-level models using large-scale data comprising new car buyers' profiles, and macro-level models using aggregated adoption data to understand and project the effects of various factors that affect the adoption rate of energy-efficient vehicles. 
INAPSARC

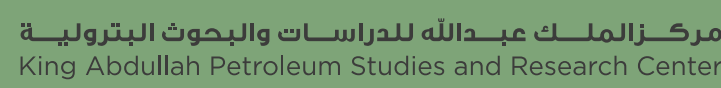

www.kapsarc.org 